\title{
BRINCAR NA RUA: RELAÇÕES ENTRE MORADORES DE CAMADAS MÉDIAS E POPULARES NO MORRO DA CAIXA
}

\author{
Viviane Kraieski de Assunção ${ }^{1}$
}

\section{Introdução}

O tema deste artigo são as relações entre moradores de camadas médias e populares do bairro do Morro da Caixa d'Água, no município de Tubarão, localizado no sul do Estado de Santa Catarina. Busco mostrar, no texto, como as brincadeiras das crianças nas ruas do bairro evidenciam diferenças - e tensões - entre os sujeitos de camadas sociais distintas experienciadas em seu cotidiano. Neste sentido, brincar (ou não) na rua serve para pensar as percepções dos sujeitos sobre o "outro" e a forma como estes indivíduos se apropriam do espaço público. Pode-se, desta forma, problematizar estes espaços, recorrentemente compreendidos como lugares do encontro e da diversidade.

Para pensar nestes usos da rua pelas crianças, é preciso antes entender o lócus da pesquisa. Exponho a importância do bairro como unidade de análise para compreender o fenômeno urbano contemporâneo, assim como as particularidades do Morro da Caixa, e como sua história é representativa de relações mais amplas que ocorrem no município de Tubarão. As relações entre os moradores aparecem marcadas pela pessoalidade, e as diferenças entre camadas sociais se encontram espacializadas nas "ruas dos pobres" e nas "ruas dos ricos".

Destaco que os dados de pesquisa aqui apresentados foram produzidos por diferentes abordagens metodológicas, dentre as quais apresento a importância de caminhar pelo bairro. Foi através destas caminhadas que pude fazer parte do cotidiano dos moradores do Morro da Caixa, de suas práticas recorrentes, de seus usos do tempo e do espaço. A partir destes deslocamentos, os discursos de meus interlocutores começaram a ganhar outros sentidos, localizados em suas práticas cotidianas. O cotidiano é destacado no texto como relevante para o acesso às experiências diárias, às ações recorrentes, que remetem a formas de organização do tempo, normas, valores, moralidades.

\footnotetext{
${ }^{1}$ Universidade do Extremo Sul Catarinense, Brasil.
} 
Deste modo, a etnografia feita na casa e na rua, ou ainda, entre a casa e a rua, recoloca a importância destas "entidades morais" ou "esferas de ações sociais" (DaMatta, 2000) para entender as relações entre moradores de camadas sociais distintas, que se diferenciam em relação ao entendimento e ao uso deste espaço.

\section{O bairro como espaço de sociabilidade}

Em 1974, o município de Tubarão foi assolado por uma grande enchente. Depois de dois dias de chuvas intensas, em 24 de março, o Rio Tubarão, que atravessa o centro da cidade, transbordou, inundando boa parte do município. A forte correnteza destruiu casas, ruas e os trilhos da estação ferroviária. A cidade ficou sem energia elétrica e rede telefônica. As águas começaram a baixar dois dias depois da inundação. Segundo dados oficiais, a enchente de 1974 causou a morte de 199 pessoas e desalojou 60 mil dos 70 mil habitantes da cidade de Tubarão na época (ver Enchente de 1974, 2007, Feuerschette, 2004, Vettoretti, 1992).

A partir deste momento, as áreas mais altas da cidade passaram a ser procuradas por moradores que temiam novas cheias do rio Tubarão. Neste sentido, entendo que, a partir da enchente de 1974, houve uma reconfiguração socioespacial do município de Tubarão. O Morro da Caixa, conhecido como local de moradia de famílias pobres, serviu de abrigo para moradores das partes mais baixas da cidade durante a enchente. Após a inundação, começou a receber moradores de camadas médias e de camadas altas.

Autores como Velho (2002) mostram a ligação de alguns bairros com determinadas camadas ou status sociais, o que também pode ser verificado no município de Tubarão. Em certos bairros concentram-se mais moradores de determinada camada social. No Morro da Caixa, no entanto, famílias de camadas médias e de camadas populares passaram a habitar o mesmo bairro após a enchente. Neste sentido, parece relevante entender o bairro através da oposição englobante-englobado, que preside a relação entre o conjunto e elemento, na qual Dumont (1997) define a hierarquia. Segundo o autor, as relações hierárquicas se apresentam em níveis diferenciados, havendo, num primeiro momento, identidade entre os elementos e, no seguinte, diferença ou oposição entre eles. Assim, o Morro da Caixa seria 
representativo das contradições sociais que se verifica no município de Tubarão de uma forma mais ampla.

Pensamos, então, que é no espaço que se expressam as hierarquias sociais. Deste modo, o espaço se apresenta como "um verdadeiro campo de forças cuja formação é desigual" (Santos, 1978: 122). Como uma totalidade, assim como a própria sociedade que o constitui, o espaço se define como um "conjunto de formas representativas de relações sociais do passado e do presente e por uma estrutura representada por relações sociais que se manifestam através de processos e funções" (Santos, 1978: 122).

A pesquisa teve, como unidade de análise, o bairro Morro da Caixa d'Água, mais conhecido apenas como Morro da Caixa, no município de Tubarão, no Sul do Estado de Santa Catarina. Não se trata de ceder às "tentações da aldeia", ou seja, de buscar um enfoque etnográfico que se limite a um pequeno grupo reduzido em sua heterogeneidade e complexidade (Magnani, 2003). Trata-se, antes, de reconhecer, assim como Fonseca, a importância dos bairros no Brasil e em demais países da América Latina, onde o local de residência está relacionado com a organização social. Nestes espaços, apesar das transformações nas cidades, as redes de vizinhança e de parentesco continuam relevantes (Fonseca, 2004: 11).

Definir o conceito de bairro constitui um desafio. Pensamos, assim como Frúgoli (2013), que não se trata de um espaço que “apresenta como uma realidade a priori”, pois "é marcado por planos e escalas distintos, fronteiras fluidas e alvo de múltiplas representações”. Além disso, sua significação pode variar de acordo com os atores sociais, as instituições e as situações em jogo, além dos interesses políticos em questão e do recorte disciplinar adotado (Frúgoli, 2013).

Ainda que não possamos apresentar uma definição única e precisa, podemos entender os bairros como "lugares sociais intermediáriosos entre pequenas unidades de vizinhança e unidades mais amplas" (Codeiro, 2001: 128), onde se constituem sociabilidades locais, além de relações de solidariedade e de conflito entre seus moradores e entre estes e indivíduos provenientes de outros contextos (Cordeiro, 2001).

Assim como a vida na cidade exige a assimilação de código, o bairro é "uma noção dinâmica que necessita de uma progressiva aprendizagem mediante a repetição do engajamento do corpo do usuário no espaço público até exercer aí uma apropriação” 
(Mayol 2009: 41-42). Ainda citando Mayol, este espaço urbano oferece incontáveis possibilidades de trajetórias, e tem como núcleo irredutível a esfera do privado (2009: 42).

Cabe também compreender o bairro como um espaço da sociabilidade, "onde se manifesta um 'engajamento' social ou, noutros termos: uma arte de conviver com parceiros (vizinhos, comerciantes) que estão ligados a você pelo fato concreto, mas essencial, da proximidade e da repetição" (Mayol, 2003: 39). Nas palavras de Magnani, o bairro especialmente o bairro popular, de periferia, é o primeiro contexto onde se pode perceber a relação entre uma forma de sociabilidade e determinada delimitação do espaço urbano.

O conceito de sociabilidade é aqui utilizado tal como definido por Georg Simmel. Para ele, diferentemente da abordagem durkheiminiana, a sociedade não é exterior aos indivíduos, mas emerge da interação entre eles. Nas palavras do autor, a sociabilidade é “o estar com um outro, para um outro, contra um outro que, através do veículo dos impulsos ou dos propósitos, forma e desenvolve os conteúdos e os interesses materiais ou individuais". (Simmel, 1983: 168).

O conflito é aqui pensado também a partir da perspectiva simmeliana, como uma forma social que emerge das interações entre os indivíduos, podendo apresentar diferentes gradações, e que representa a "negação da unidade" (Simmel, 1983).

As relações de reciprocidade entre os vizinhos também são vistas de forma ampla, podendo ser tomadas em seus sentidos positivo e negativo. Isso abrange, segundo Clastres (1980), tanto relações de trocas e os intercâmbios (de favores, bens, serviços etc.), no sentido positivo, como também o das guerras, vinganças, sequestros, em seu sentido negativo. É a partir desta perspectiva que a unidade social não existe apenas a partir da ausência de conflitos. Ao contrário, o conflito seria um mediador das relações em uma estrutura social (Gluckman,1986).

\section{Caminhando pelas ruas do Morro da Caixa}

Estas relações entre os moradores do bairro foram pesquisadas por meio de trabalho de campo etnográfico realizado em dois momentos distintos: o primeiro foi realizado no ano de 2006, e que foi retomado no ano de 2014. Através de observações sistemática e participante, próprias da etnografia de rua, “o antropólogo percebe a cidade como objeto 
temporal, lugar de trajetos e percursos sobrepostos, urdidos numa trama de ações cotidianas" (Rocha e Eckert, 2003). Fazem parte desta etnografia "percorrer as paisagens que conformam um território, seguir os itinerários dos habitantes, reconhecer os trajetos, interrogar-se sobre os espaços evitados" (Rocha e Eckert, 2003), conformando espaço e tempo através do movimento pela paisagem urbana.

Através do caminhar, foi possível observar as formas de apropriação do espaço pelos moradores e entender de que formas este espaço é atravessado por fluxos de pessoas. Como aponta De Certeau (2004), a cidade é inseparável das práticas dos sujeitos que a habitam. Neste sentido, o caminhar é comparável ao ato de falar, já que se constitui em um ato de enunciação. Assim, a cidade pode ser interpretada, como uma linguagem textual, através do ato de caminhar por ela. Nas palavras do autor, "o caminhar é uma enunciação pois o pedestre se apropria do sistema topográfico (como nos apropriamos da língua), faz do lugar um espaço (como fazemos da língua um som) e se relaciona com a cidade através dos seus movimentos".

É este entendimento que torna possível entender a existência de uma "retórica da caminhada". Esta implica usos e estilos. Enquanto os últimos denotam a singularidade de cada indivíduo, os primeiros remetem às normas. Segundo De Certeau, ambos se cruzam para formar um estilo do uso, uma maneira de ser e maneira de fazer.” (Certeau, 2004: 180).

Através das caminhadas, os discursos de meus sujeitos de pesquisa passaram a adquirir outros sentidos. Como afirma Certeau, "todo relato é um relato de viagem - uma prática no espaço" (2009: 183). Estes relatos não apenas transpõem os deslocamentos para o campo da linguagem, mas também possuem um papel ativo, pois "produzem geografias de ações" e "organizam a caminhada" (Certeau, 2004: 183).

Esta caminhada ocorreu pelas ruas do bairro, que podem ser compreendidas como "espaços de circulação", mas também enquanto "lugar e suporte de sociabilidade" (Magnani). A rua, afirma o autor parafraseando Levi-Strauss, é “boa para pensar":

É a rua que resgata a experiência da diversidade, possibilitando a presença do forasteiro, o encontro entre desconhecidos, a troca entre diferentes, o reconhecimento dos semelhantes, a multiplicidade de usos e olhares - tudo num espaço público e regulado por normas também públicas. Este é o espaço que se opõe, em termos de estrutura, 
àquele outro, o do domínio privado, da casa, das relações consanguíneas (DaMatta, 1985; Magnani, 1993)

Caminhar pelas ruas permite que o pesquisador se depare com diferentes discursos e práticas, que oferecem diferentes formas de ver e atribuir sentidos:

\begin{abstract}
A rua que interessa e é identificada pelo olhar antropológico é recortada desde outros e variados pontos de vista, oferecidos pela multiplicidade de seus usuários, suas tarefas, suas referências culturais, seus horários de uso e formas de ocupação. A rua, rígida na função tradicional e dominante - espaço destinado ao fluxo - às vezes se transforma e vira outras coisas: vira casa (Santos e Vogel, 1985)

vira trajeto devoto em dia de procissão, local de protesto em dia de passeata, de fruição em dia de festa, etc. Ás vezes é vitrine, outras é palco, outras ainda lugar de trabalho ou ponto de encontro. (Magnani, 1993)
\end{abstract}

Foi através das caminhadas pelo bairro que me aproximei da vida cotidiana das ruas dos bairros. O cotidiano é entendido por Heller (1985: 3) como a vida de todos os dias, vivida por todas as mulheres e homens em qualquer tempo ou lugar. Kosik (1989) esclarece que o cotidiano expressa a existência de seres humanos no mundo, através da repetição de tarefas e atividades diárias essenciais para sua vivência. O modo de organização de suas vivências e as redes de relações que são construídas formam a cotidianidade.

Essas tarefas cotidianas, no entanto, podem ser pensadas além de atividades repetitivas. A dimensão do cotidiano, como sugerem alguns autores, é um lugar central de reprodução social. Para Lefebvre, a partir da formação da "sociedade burocrática de consumo dirigido", o cotidiano passa a ser programado por forças sociais e políticas que estão além dos sujeitos que vivem nas cidades. Estas forças teriam o poder, segundo o autor, de planejarem as atividades dos moradores urbanos, tornando-as mais funcionais. Esta estruturação seria semelhante à de uma grande empresa moderna, que possui influência não apenas na arena econômica, como também nos cotidiano das pessoas. Este modelo é imposto tendo a racionalidade como valor de organização e melhor funcionamento da sociedade (Lefebvre, 1991). ${ }^{2}$

\footnotetext{
${ }^{2}$ Wilk lembra que tanto para Durkheim quanto para Weber, o comportamento rotinizado, executado sem reflexão, era associado aos animais, aos primitivos e as chamadas "sociedades tradicionais", não-modernas. Já a consciência reflexiva e a racionalidade eram relacionadas às sociedades modernas. Segundo Wilk, para Durkheim e Weber eram bastante otimistas em relação à modernização, pois acreditavam que esta liberaria as pessoas dos constrangimentos dos hábitos, e criaria no futuro uma vida baseada no improviso, na reinvenção diária. (Wilk, 2009: 144)
} 
Já Michel de Certeau propõe que o cotidiano também é um terreno potencial de resistência e subversão, e não apenas de complacência e passividade, como sugerem as análises de Lefebvre. $\mathrm{O}$ autor afirma que o cotidiano é formado por tempo e espaço onde se configuram as táticas que os atores sociais desenvolvem para lidarem com as ações engendradas por aparatos dominantes de repressão. Assim como há sistemas que normatizam a vida cotidiana, como pensa Lefebvre, há, para Certeau, espaço para ações de resistência dos sujeitos, através de microações diárias (Certeau 2008).

É importante considerar que há implicações temporais em todas as práticas sociais contemporâneas. Aqui, o tempo não é apenas um recurso, mas também parte integrante em um sistema de práticas no qual estamos todos engajados. Como mostra Shove, há uma relação estreita entre tempo e rotina: por um lado, o tempo pode ser tomado como um recurso contemporâneo escasso que as práticas consomem e, por outro, o ritmo da vida social está na base da categoria tempo. Deste modo, há uma constituição mútua entre tempo e prática, pois são os arranjos temporais que provém da reprodução efetiva da vida diária, ou, nas palavras da autora, as práticas fazem o tempo (Shove, 2009: 17).

O tempo é pontuado por eventos extraordinários, como morte e nascimento, mas também é organizado através de uma variedade de eventos ordinários, como dormir, comer, assistir a televisão (Shove, Trentmann e Wilk, 2009: 02), ou ainda brincar na rua, como exponho mais adiante. A noção de tempo não contempla apenas a conotação de coordenação e ritmo, pois envolve ainda dimensões materiais, emocionais, morais e políticas.

O aumento da velocidade da sociedade e a experiência de estar apressado e ocupado não é apenas objeto de discussão de diversos autores, como também aparece nos discursos dos sujeitos de pesquisa sobre suas vivências cotidianas. Como sugere Shove, já que o tempo é parte da prática, deve-se focar não apenas no ritmo de vida ou encurtamento de distâncias, mas sobre novas configurações e modos de fazer, ${ }^{3}$ que tomam forma em torno de meios tecnológicos, como tecnologias móveis, ou ainda com meios e modos mais rápidos de viagem (Shove, 2009: 26).

\footnotetext{
${ }^{3}$ Neste sentido, a autora sugere o estudo de atividades como o ir e voltar do trabalho, a realização de várias tarefas simultaneamente, e ainda as viagens curtas, de apenas um dia de duração (commuting, multi-tasking, day tripping).
} 
Devemos também considerar que rotina não é um termo neutro, mas está carregado de significados. Segundo Slater, precisamos observar não apenas os aspectos empíricos da rotina, como também os aspectos éticos e normativos da noção de rotina. $\mathrm{O}$ autor explica que noções como rotina e seus cognatos são rotulados de acordo com status sociais particulares e valor a formas de ação e prática, e são estrategicamente estabilizadas de formas específicas. De acordo com Slater, definir uma estrutura de ação como rotina já contém uma moldura ética e um julgamento de valor. Para Slater, a rotina é um termo performativo, e não apenas um descritor, e é uma noção através da qual as práticas são estruturadas e valorizadas (Slater, 2009).

Finalmente, esta rotina, para além de sua concepção como atividades organizadas e repetidas de forma recorrente, não pode também ser pensada de forma individualizada. As rotinas de membros de uma mesma família, apesar de poderem ser diferenciadas, estão em inter-relação, assim como as rotinas $d$ os vizinhos.

Foi por meio das caminhadas pelas ruas do Morro da Caixa, como prática rotineira de meu trabalho de campo, que, aos poucos, passei também a fazer parte do cotidiano dos sujeitos de minha pesquisa. Assim passei a conhecer a vida dos moradores, e a ser conhecida por eles.

\section{Ninguém mora no Morro da Caixa}

Duas perguntas eram frequentes quando eu conhecia algum morador do Morro da Caixa. Primeiro, perguntavam-me: Onde tu moras? Em seguida: Tu és filha de quem? Estas perguntas apontam para duas questões importantes para se entender o Morro da Caixa e, mais amplamente, o município de Tubarão. O local onde se mora e a filiação "dizem" quem a pessoa é.

O centro da cidade de Tubarão é o lugar mais valorizado pelo mercado imobiliário, onde se concentra o comércio e moram os chamados "ricos" do município. No centro, localizam-se o hospital da cidade (que também atende pacientes dos municípios vizinhos menores), a Catedral, a Praça Sete de Setembro, a Prefeitura, e, mais recentemente, o Shopping Center. É onde se concentra o maior número de prédios comerciais e residenciais da cidade. 
Em volta do centro, ficam os bairros residenciais (como Oficinas, Vila Moema, Humaitá, entre outros) habitados majoritariamente por camadas médias. A zona rural como o bairro Madri e Passo do Gado - é mais afastada do centro, onde estão pequenas e grandes fazendas do município, e bairros periféricos, por exemplo, Campestre e Passagem, habitados por camadas mais populares.

Pode-se dizer que o bairro do Morro da Caixa é bastante representativo das relações entre local de residência e camada social do município de Tubarão. Em uma das minhas visitas ao bairro, ouvi uma de minhas interlocutoras falar a uma conhecida que passava de bicicleta: "Não te vi mais. Só passa agora na rua dos ricos?" O comentário chamou-me a atenção. A senhora me explicou que chama as ruas pavimentadas, onde ficam as melhores casas, das camadas médias, de "rua dos ricos". Já o lugar onde mora, de chão batido, e de casas mais simples, é a "rua dos pobres". A filha desta senhora disse-me que "muita gente tem medo de passar por ali”. De fato, existe uma tensão entre os moradores, que pode ser exemplificada pelos modos diferenciados em que os filhos são criados, que exponho mais adiante.

As duas principais ruas do Morro da Caixa, onde concentrei minha etnografia, são bastante extensas. Uma delas vai do centro da cidade até o alto do morro do Caeté, que é o fim do bairro do Morro da Caixa. Já a outra rua corta o bairro de Oficinas e também termina no Morro. É a partir do cruzamento com uma outra avenida que passa a pertencer ao Morro da Caixa. Estas duas ruas são pavimentadas, e nelas ficam as casas das camadas médias, e algumas das camadas mais altas, como as que pertencem a um vereador e a um empresário. As ruas principais têm alguns becos, que não apresentam nomes de ruas. São vias tortas, onde se concentram as casas das camadas mais populares. Estas casas são feitas principalmente de madeira, e muitas delas não são pintadas. As ruas são de chão batido, e tem sistema de esgoto precário.

A existência da "rua dos pobres" e da "rua dos ricos" mostra que, apesar de indivíduos de classes sociais distintas habitarem o mesmo bairro, é possível perceber a permanência de uma segregação espacial entre estes moradores.

O local de residência e a filiação “dizem” quem se é, como afirmei anteriormente. São, por essa razão, fundamentais em grupos regidos pela lógica da hierarquia (Dumont, 
1997), como é o caso das camadas populares no Brasil (DaMatta, 1997; Duarte, 1986). Estes fatores participam do processo de construção da identidade dos moradores.

Convivendo com os moradores, percebi que muitos deles não se referiam ao lugar onde residem como Morro da Caixa. Vários de seus habitantes dizem que moram na continuação do bairro de Oficinas, que é ao lado. Quando fornecem o endereço, informam apenas o nome da rua. Explicaram-me também que ali não há uma caixa d’água da empresa de abastecimento do município, mas que esta caixa está localizada no Fábio Silva, bairro vizinho, e que, por essa razão, não há sentido em dizer que moram no Morro da Caixa. É interessante perceber, nas explicações de alguns moradores, que o bairro está negativamente associado a um lugar de famílias pobres e de negros. Frequentemente adotam uma posição de defesa ao se referirem ao bairro, como pode ser percebido nos discursos dos moradores relatados abaixo.

Tem gente que é muito bairrista. Me falavam: você vai morar no Morro? Mas aqui nunca ninguém mexeu em nada. Uma quadrilha foi presa por roubo em um prédio em Oficinas. (Marisa, 42 anos)

Falavam para mim que o bairro não era bom, que era o lugar de gente malencarada. Mas não importa o lugar. O que importam são as pessoas. (Dona Isabel, 67 anos)

(...) hoje em dia ninguém mais diz que mora no Morro da Caixa. Todo mundo diz que mora em Oficinas. (Dona Maria das Dores, 62 anos)

Segundo os moradores, o bairro é conhecido por ser o lugar de ladrões e traficantes de drogas. Ninguém soube identificar quem são estes moradores. Eram sempre apontados como residentes em regiões mais altas do Morro. "Eles não moram aqui não... eles vivem mais pra lá...", afirmou-me uma interlocutora. Apenas uma moradora disse-me que seu vizinho era ladrão, e me informou que nenhum morador ali deixava as portas das casas abertas quando saía para que não fosse roubado. Mas este discurso também apresenta contradições. Ela acredita que a presença de vizinhos ladrões representa perigo apenas para "os ricos", as camadas médias, e que há um sentimento de proteção entre os moradores que são vizinhos de traficantes. "A gente não mexe com eles, eles não mexem com a gente”, disse-me uma das interlocutoras. Para os moradores da "rua dos pobres", os estreitos laços 
de vizinhança torna o lugar mais seguro: "aqui todo mundo se conhece. Quando tem uma pessoa estranha, a gente logo sabe que não é daqui".

Este sentimento não é compartilhado por moradores de maior poder aquisitivo. Muros altos, grades nas janelas, cercas elétricas e cães de guarda demonstram as tentativas destes moradores de evitarem furtos e assaltos. As casas de algumas famílias de camadas médias podem ser descritas como enclaves fortificados - termo criado por Caldeira (2000) para definir tipos de moradias, principalmente condomínios fechados, construídas tendo como princípios básicos a segurança, o isolamento, a homogeneidade social, equipamentos e serviços. As casas com muros e grades, e monitoradas por câmeras de segurança e empresas especializadas demonstram as tentativas dos moradores de imporem regras de inclusão e exclusão naquele espaço, através de barreiras físicas. Torna-se uma nova forma de segregação espacial, distanciando-se de outros moradores de classes sociais com menor poder aquisitivo (Caldeira, 2000).

De acordo com os participantes da pesquisa, as representações negativas sobre o Morro da Caixa teriam mudado após a enchente. A vinda de moradores de classes mais elevadas para a localidade fora acompanhada pelo aumento da infraestrutura, como luz elétrica (que até a inundação não havia na comunidade), iluminação pública, rede de esgoto e pavimentação nas ruas.

O aumento da procura por imóveis para vender e alugar na localidade, tem sido percebido por moradores que vivem no local desde antes da enchente de 1974:

Esses dias passou uma senhora de carro perguntando se tinha alguma casa para comprar,
porque ela queria morar aqui. Eu fiquei pensando: meu Deus, agora tem gente que quer
morar no Morro! Que mudança! (Silvana, que vive na localidade há 35 anos)

Você pode perceber que já não tem mais espaço para construir. Não tem mais terreno vazio. Está tudo ocupado. Antes tinha muito espaço. Ninguém queria morar aqui. Morava porque precisava, por necessidade. (Marlene, moradora do Morro há 42 anos)

Esta procura de residências no Morro da Caixa também foi acompanhada por uma valorização imobiliária. Todos os entrevistados pela pesquisa, que residem no Morro desde antes da enchente de 1974, garantem que não conseguiriam adquirir um imóvel no local atualmente. Neste sentido, o depoimento de Ana é bastante representativo: "Eu moro onde 
meus pais moraram a vida inteira. Antes ninguém queria morar aqui. Agora, para comprar uma casa aqui, só mesmo rico".

\section{Todo mundo se conhece"}

Segundo os próprios moradores, o Morro da Caixa é um bairro com muita fofoca. A fofoca acontece nas conversas de portão entre vizinhas, entre mulheres sentadas na rua, no encontro entre vizinhos na padaria.

Aqui a gente tem que ficar de boca fechada. É muita fofoca. Por qualquer coisa já tem briga. (Sueli)

Aqui tem muita fofoca. Todo mundo diz isso. Mas desde que não falem de mim... (Dona Maria das Dores)

A fofoca tem sempre conotação negativa. Os moradores afirmam ter muita fofoca no bairro, mas nenhum deles se admite fofoqueiro. E ninguém quer ser vítima de fofoca. Essa mesma observação foi feita por Fonseca (2000) em uma etnografia na Vila do Cachorro Sentado, de grupos de camada popular em Porto Alegre.

A fofoca envolve, pois, o relato de fatos reais ou imaginários sobre o comportamento alheio. Ela é sempre concebida como uma força nefasta, destinada a fazer mal a determinados indivíduos. Ninguém se considera fofoqueiro, mas todo mundo concorda em dizer que há fofoca constantemente na vizinhança. (Fonseca, 2000: 41)

A autora cita interpretações antropológicas para se compreender a fofoca. A fofoca pode criar uma história social do grupo, reforçando o sentimento de pertencimento à comunidade. Pode também servir para delimitar os limites do grupo, integrando ou excluindo indivíduos. Além disso, pode ter a função educativa, ensinando princípios morais, ou ser uma importante fonte de informação. Serve ainda para informar a reputação dos moradores de determinado lugar. Esta última é a que a autora identifica como a mais relevante para entender a fofoca no grupo que estudou.

No Morro da Caixa, variados assuntos são temas de fofocas: separação de casais, brigas entre familiares e vizinhos, tentativas de suicídio, a suposta prostituição de certas 
mulheres, os maus-tratos aos filhos. A fofoca é, como mostra Fonseca, domínio feminino por excelência. É a contrapartida das mulheres em uma rede de trocas simbólicas.

No Morro da Caixa, todo mundo se conhece. Sabe-se o nome, em que casa mora, quem são os pais, a profissão. Ouvi várias vezes comentários entre vizinhas sobre pessoas que passavam nas ruas. Tentavam descobrir onde moravam, de quem eram filhos ou parentes, e o que estavam fazendo ali. Isso aconteceu com minha presença constante no bairro. Enquanto andava pelas ruas, moradores me cumprimentavam e faziam-me perguntas. As relações são marcadas pela pessoalidade, uma situação semelhante à encontrada por Prado (1987) na cidade de Cunha, interior de São Paulo.

O reconhecimento é, portanto, algo básico nesse sistema; reconhecimento no sentido de saber-se quem é quem. E, em paralelo com isso, a confiança, na medida que todos são identificados, ou rapidamente identificáveis, pela relação com alguém. (Prado, 1987: 52)

Prado cita o trabalho de DaMatta. Para este autor, em cidades pequenas, a expressão você “sabe com quem está falando?", que expressa as relações hierárquicas e autoritárias nas sociedades brasileiras, não faz sentido.

\footnotetext{
Numa cidade pequena não se usa essa forma de fuga do anonimato, simplesmente porque o anonimato não existe. $\mathrm{O}$ mesmo ocorre em sociedades tribais onde a posição numa família, o fato de se possuir um certo conjunto de nomes ou de se pertencer a uma dada linhagem.
}

\section{Criação dos filhos: na rua $\mathrm{x}$ no pátio}

Magnani ressalta que a rua é o espaço, por excelência, da sociabilidade, do encontro entre os diferentes: "Sem esse tipo de contato, as pessoas ficariam restritas ao convívio entre os iguais, confinadas ao espaço doméstico", esclarece o autor. A partir do trabalho de Roberto DaMatta, Magnani lembra que a oposição entre casa e rua traduz a oposição entre espaço público e espaço doméstico, cada qual representando um conjunto de características. Neste sentido, “a "casa", que representa o domínio do privado, é o espaço das relações de sangue, do contato íntimo, da segurança; "rua", ao contrário, é o domínio do público, das oportunidades, dos estranhos, e também do perigo". O autor retoma expressões cotidianas 
ditas para as crianças, para mostrar que estas conhecem bem estas diferenças entre a casa e a rua: "Já pra casa, menino!" e "Que está fazendo até essa hora na rua?".

Magnani propõe, a partir de pesquisas antropológicas desenvolvidas na periferia e em regiões centrais da cidade de São Paulo, que há um espaço intermediário entre a casa e a rua, o "pedaço". O autor esclarece que se trata de uma associação entre ambos: "é quando, de um lado, a casa se abre para fora e, de outro, a rua se torna mais acolhedora: do encontro, da interseção entre ambos é que surge o pedaço". A definição de pedaço é feita pelo autor a seguir:

O termo, na realidade, designa aquele espaço intermediário entre o privado (a casa) e o público, onde se desenvolve uma sociabilidade básica, mais ampla que a fundada nos laços familiares, porém mais densa, significativa e estável que as relações formais e individualizadas impostas pela sociedade. Pessoas de pedaços diferentes, ou alguém em trânsito por um pedaço que não o seu, são muito cautelosas: o conflito, as hostilidades estão sempre latentes, pois todo lugar fora do pedaço é aquela parte desconhecida do mapa e, portanto, do perigo. Para além da soleira da casa, portanto, não surge repentinamente o resto do mundo. Entre uma e outro situa-se um espaço de mediação cujos símbolos, normas e vivências permitem reconhecer as pessoas diferenciando-as, o que termina por atribuir-lhes uma identidade que pouco tem a ver com a produzida pela interpelação da sociedade mais ampla e suas instituições. (Magnani, 1998: 116-117)

Pode-se dizer que algumas ruas do Morro da Caixa constituem um pedaço, no sentido dado por Magnani, por constituirem espaços de sociabilidade de crianças e adolescentes, que se reúnem diariamente, principalmente ao final da tarde, para brincarem. Neste sentido, este espaço participa da constituição de identidades do grupo. Ressalto, no entanto, que apenas as crianças de camadas populares brincam nas ruas e ocupam este pedaço, diferenciando-se através de suas práticas neste espaço.

$\mathrm{O}$ ato de brincar, como afirmam Müller et al., pode expressar as desigualdades sociais que atravessam o cotidiano das crianças e de suas famílias. Nas palavras das autoras, as brincadeiras podem diferenciar pobres e ricos: "na hora de brincar, uns brincam com o que desejam brincar e os outros, brincam com o que tem e principalmente com o que não tem" (Müller, 2007: 03). Meu trabalho de campo demonstrou que o local onde se brinca também pode ser um elemento diferenciador. Neste caso, a utilização da rua como espaço da brincadeira marca o cotidiano das crianças de camadas mais pobres. 
Caminhando pelas ruas do Morro da Caixa, é possível encontrar crianças de diferentes idades em todos os períodos do dia. No entanto, elas são mais frequentes nos finais de tarde, após o período escolar. Uma das brincadeiras mais frequentes é jogar futebol, ou "jogar bola", como dizem. As bolas são motivos de conflitos entre as crianças e os moradores de camadas médias. Segundo eles, as bolas podem quebrar vidraças e as crianças pulam os muros das casas para recuperar as bolas.

Márcia morava em um apartamento no Centro da cidade, e foi morar no Morro da Caixa há três anos quando a situação financeira da família piorou. Ela não gosta que os filhos dois meninos gêmeos de oito anos de idade brinquem com as crianças da vizinhança, porque eles aprendem "palavrões e comportamentos de crianças mal-educadas". Ela repreende os meninos por a chamarem de "minha nega": "isso eles aprenderam na escola, com as outras crianças de lá”. Na casa de Márcia, foi construída uma varanda, que é protegida por uma tela, para que os filhos brinquem sem o contato das crianças da rua.

Fátima também não gosta que o neto de nove anos que ela cria desde bebê para que a filha possa trabalhar brinque com outras crianças do Morro da Caixa. A criança está sempre próxima a ela. Fátima não presenteou o neto com uma bicicleta com receio de que ele "suba o Morro": "Prefiro que ele desça", afirmou-me, o que significa ir em direção ao centro da cidade.

Segundo a dona-de-casa, o contato com outras crianças do bairro poderia levar o menino a adquirir maus comportamentos, como falar palavrão, fumar cigarro, beber (álcool). Além disso, há o perigo dos ajuntamentos, que é o agrupamento de jovens nas ruas, que geram a "bagunça". Os “ajuntamentos" são vistos negativamente. Alguns moradores diziam-me para evitar passar por grupos de rapazes, porque estes podiam "mexer" comigo.

Estar na rua não é perigoso apenas para as crianças, mas também para as mulheres. Estas não podem viver na "costeira", que seria frequentar constantemente a rua e a casa de vizinhos. A mulher "costeirenta" é acusada de descuidar-se dos trabalhos domésticos e do cuidado com os filhos, e corre o risco de ficar "mal falada" na vizinhança.

Nas camadas mais populares, as crianças têm maior liberdade para andar e brincar na rua. Léia repreende Iara por esta se preocupar quando o filho está na rua. Para a avó, a criança deve brincar fora de casa. "Criei todos os meus filhos na rua, e nunca aconteceu 
nada. Estão aí todos fortes". Ela acredita que, na rua, as crianças adquirem mais força e aprendem a se defender dos possíveis perigos.

Outros comportamentos de moradores de camadas populares são bastante criticados e temidos pelos das camadas médias no Morro da Caixa. Da varanda do segundo piso de sua casa, Ivete observa os vizinhos. Do lado de sua casa, estão as casas dos mais pobres. Ela não aprova o comportamento destes moradores, e pontua sua presença nas ruas:

\footnotetext{
As crianças estão sempre na rua. Os adultos também. O que será que eles fazem? Por que os pais não incentivam as crianças a estudarem? Aquele menino lá não vai à escola há três dias. Eu perguntei para a mãe dele. Ela me disse que ele não estava indo para escola porque tinha extraído um dente e não podia pegar sol. Mas ele está aí no sol. Na escola, dentro da sala, ele não pega sol. Aquele outro menino, que tem dez anos, mal sabe ler. Os meus filhos [agora com 24, 22 e 18 anos] entraram no colégio com cinco anos e já sabiam ler".
}

Ivete também destaca outro "mau comportamento" dos vizinhos que é uma crítica comum entre os moradores de camadas médias: as brigas, e pontua como seus conflitos ultrapassam os limites do espaço privado da residência: "Eles são muito barraqueiros. Tem briga entre marido e mulher, vizinhos ... Sempre junta todo mundo para ver. Dá até polícia. Eu vou para dentro de casa e prefiro nem ver!"

Em um dos primeiros dias de campo, acompanhei uma delas da casa de Iara, que fica na "rua dos pobres". Enquanto tomava café com sua tia, Iara saiu correndo para a rua: "é briga!”. Os outros moradores fizeram o mesmo. Dirigiram-se para a rua em que uma das vizinhas discutia com o ex-marido, que se recusara a voltar para a casa. A mulher pegou um tijolo para atirar no ex-marido, e foi contida pela mãe. Os outros vizinhos apenas observavam. Iara explicou-me: "Aqui é assim. Todo mundo assiste, mas ninguém se mete". A discussão acabou quando o homem foi embora. Os moradores então voltaram para as casas.

Esta e outras brigas que ocorreram no Morro da Caixa mostram que os moradores oscilam entre duas opiniões opostas: a de que, no Morro, todo mundo se conhece e todo mundo sabe da vida de todo mundo e a ideia de que ninguém se mete na vida dos outros. Como demonstra DaMatta (1997), na sociedade brasileira estes dois pensamentos, uma própria de sociedades holistas e tradicionais, e outra típica de sociedades modernas e igualitárias, são utilizadas dependendo do contexto. Desta forma, ora podemos ser tratados 
como indivíduos, ora como pessoas. Quando vítimas de fofocas, os moradores reclamam o direito de serem indivíduos.

\section{Considerações finais}

A jornalista e socióloga estadunidense Jane Jacobs, em livro lançado originalmente em 1961, criticou as cidades modernas, e defendeu que as cidades deveriam ser "vivas". Para isso, as ruas e calçadas deveriam ter fluxo constante, e assim como os demais espaços públicos, deveriam ser usadas e ocupadas constantemente. Segundo Jacobs, esta movimentação traria maior seguranças para todos. Ao invés de contar apenas com aparatos de vigilância e policiais, os "olhos das ruas" dos moradores e transeuntes garantiriam a segurança, através de uma "[...] rede intrincada, quase inconsciente, de controles e padrões

de comportamento espontâneos presentes em meio ao próprio povo e por ele aplicados". (Jacobs, 2000: 32)

Não se trata aqui de analisar a proposta de Jacobs, mas de utilizá-la para fazer um contraponto aos dados da pesquisa que foram expostos anteriormente. A rua, como espaço do encontro e da diversidade, é visto por moradores de camadas médias como espaço do medo. Há uma cultura do medo (Eckert, 2000), que leva a uma exacerbação dos cuidados com a segurança, a negação do encontro com o diferente e a promoção da segregação socioespacial. Neste sentido, percebemos que práticas cotidianas, como o brincar nas ruas, são vedadas a crianças desta camada social, ou ainda que estar ou ficar nas ruas pode ser algo depreciativo. Vemos então que há relações intrincadas entre espaço e cotidiano, e como estas "práticas espacializadas" promovem diferenciações entre os sujeitos residentes no mesmo bairro.

\section{Referências}

CALDEIRA, Teresa Pires do Rio. Cidade de Muros: crime, segregação e cidadania em São Paulo. São Paulo: Edusp, 2000.

CLASTRES, Pierre. Recherches d'antropologie politique. Paris: Éditions du Seuil, 1980. 
CORDEIRO, Graça Índias. Territórios e identidades sobre escalas de organização sócio-espacial num bairro de Lisboa. Revista Estudos Históricos, Rio de Janeiro, n. 28, p. 1-16, 2001. Disponível em <http://www.cpdoc.fgv.br/revista/arq/313.pdf> Acesso em 20 setembro 2014.

CORDEIRO, Graça Índias. Um lugar na cidade: quotidiano, memória e representação no bairro de Bica. Lisboa: Dom Quixote. 1997.

CORDEIRO, Graça Índias; COSTA, Antônio Firmino da Costa. Bairros: contextos e intersecção. In: Velho, G. (org.) Antropologia urbana: cultura e sociedade no Brasil e em Portugal. Rio de Janeiro, Jorge Zahar Editor, 1999. p. 58-79.

DUMONT, Louis. Homo Hierarchicus: o sistema das castas e suas implicações. 2. ed. São Paulo: EDUSP, 1997.

DAMATTA, Roberto. A Casa \& A Rua: Espaço, Cidadania, Mulher e Morte no Brasil, Ed. Rocco Ltda, RJ, 2000.

DE CERTAU, Michel. A Invenção do Cotidiano: 1. Artes de Fazer. Petrópolis/RJ: Vozes. 1994.

DUARTE, Luiz Fernando. Da vida nervosa: nas classes trabalhadoras urbanas. Rio de Janeiro; J. Zahar Editor; Brasilia: CNPq, 1986.

ECKERT, Cornelia. A cultura do medo e as tensões do viver a cidade: narrativa e trajetória dos velhos moradores de Porto Alegre. Iluminuras, 18, 2000.

ECKERT, Cornelia e ROCHA, Ana Luiza Carvalho da. "Etnografia de Rua: Estudo de Antropologia Urbana”. In: RUA, Revista do Núcleo de Desenvolvimento da Criatividade da Unicamp - NUDECRI - Campinas, março 2003, número 9. pp. 101 a 127.

Enchente de 74 - A força de um povo que soube reconstruir sua história. Ano1, n³, Tubarão, 2007.

FEUERSCHETTE, Irmoto José. Uma direção para a vida: memórias da enchente de Tubarão 1974. Tubarão: Reuter, 2004.

FONSECA, Claudia. Família, fofoca e honra: etnografia das relações de gênero e violência em grupos populares. $2^{\mathrm{a}}$ ed. Porto Alegre: Editora da UFRGS, 2004.

FRUGOLI JR., Heitor. Relações entre múltiplas redes no Bairro Alto (Lisboa). Rev. bras. Ci. Soc., São Paulo, v. 28, n. 82, June, 2013.

Disponível em: <http://www.scielo.br/scielo.php?script=sci_arttext\&pid=S010269092013000200002\&lng=en\&nrm=iso>. Acesso em: 28 de setembro de 2014.

GLUCKMAN, Max. Análise de uma Situação Social na Zululândia Moderna. In:

BIANCO, Bela Feldman (Org.). Antropologia das Sociedades Complexas. São Paulo: Ed. Global, 1986. p. 237-365

HELLER, Agnes. O Cotidiano e a História. São Paulo: Paz e Terra, 1985. 
KOSIK, Karel. A dialética do concreto. São Paulo: Paz e Terra, 1989.

JACOBS, Jane. Morte e vida de grandes cidades. São Paulo: Martins Fontes, 2000.

LEFEB VRE, Henri. A Vida Cotidiana no Mundo Moderno. São Paulo: Ática, 1991.

MAGNANI, José Guilherme. A rua e a evolução da sociabilidade. Revista Digital de Antropologia Urbana, 1993. Disponível no site: http//www.aguaforte.com/antropologia/osurbanitas.html

MAGNANI, José Guilherme, Festa no Pedaço. São Paulo: Editora Hucitec, 1998, p. 116-117

MAYOL, Pierre. "Morar”. In: CERTEAU, Michel; GIARD, Luce; MAYOL, Pierre. A invenção do cotidiano: 2.morar, cozinhar. Petrópolis: Vozes, 2009. pp.35-185.

MÜLLER, Verônica Regina et al. O brincar das crianças: aproximações às culturas infantis. Revista Digital - Buenos Aires - Año 11 - N 104 - Janeiro de 2007

PRADO, Rosane. Mulher de Novela e Mulher de verdade: Estudo sobre cidade pequena, mulher e telenovela. Dissertação (Mestrado). UFRJ. Museu Nacional, Rio de Janeiro, 1987.

SANTOS, M. Por uma Geografia Nova. São Paulo: Hucitec, Edusp, 1978.

SHOVE, Elizabeth. "Everyday Practice and the Production and Consumption of Time". In:

SHOVE, Elizabeth, TRENTMANN, Frank, WILK, Richard (ed.). Time, Consumption and Everyday Life: Practice, Materiality and Culture. Oxford: Berg, 2009. pp. 17-34

SHOVE, Elizabeth, TRENTMANN, Frank, WILK, Richard. "Introduction". In: SHOVE, Elizabeth, TRENTMANN, Frank, WILK, Richard (ed.). Time, Consumption and Everyday Life: Practice, Materiality and Culture. Oxford: Berg, 2009. pp. 1-16

SIMMEL, G. 1983[1917] "Sociabilidade um exemplo de sociologia pura ou formal", in: MORAES, E. (org.), Sociologia: Simmel, São Paulo, Ática, p. 165-81.

SIMMEL, Georg, A natureza sociológica do conflito. In: MORAES FILHO, Evaristo (org.).

Simmel, São. Paulo, Ática, 1983.

SLATER, Don. "The Ethics of Routine: Consciousness, Tedium and Value”. In: SHOVE, Elizabeth, TRENTMANN, Frank, WILK, Richard (ed.). Time, Consumption and Everyday Life: Practice, Materiality and Culture. Oxford: Berg, 2009. pp. 217-230

VELHO, Gilberto. A utopia urbana: um estudo de antropologia social. 6a. ediÁ,,o. Rio de Janeiro: Zahar, 2002.

VETTORETTI, Amado. História de Tubarão: das origens ao século XX. Tubarão, SC: INCOPEL, 1992.

Recebido em: 29/09/2014

Aprovado em: 10/11/2014 